\title{
DETERMINING PROPERTIES OF NICKEL BASED COMPOSITE THAT REINFORCED BY ELECTROLESS NICEL PLATED BORON NITRIDE AND ASTALOY-CrM POWDERS
}

\author{
Ahmet YÖNETKEN 1,* \\ ${ }^{1}$ Material Science and Engineering, Engineering Faculty, Afyon Kocatepe University, Afyonkarahisary, Turkey
}

\begin{abstract}
Industrial development brings with it the need for new materials every day. When it comes to obtaining more than one feature together, composite materials are at the forefront of the material groups. In composite materials, the main matrix and reinforcement element are defined and known according to the material group and the morphology of the reinforcement elements. Electroless nickel plating process is the chemical coating of nickel and its alloys on metal surfaces without using electric current by the immersion method. This process is also preferred in many areas in industrial applications for improving surface wear resistance of metallic and ceramic powders. These metallic and ceramic powders are used for reinforcement to production of nickel base composite in this study. For this purpose Ni coated $(1.66 \% \mathrm{BN}$ ceramic $+31.65 \%$ Astaloy-CrM metallic) $+\% 66,67 \mathrm{Ni}$ nickel powders were shaped circularly in uniaxial cold press. These samples are sintered in conventional furnace with argon atmosphere at the temperature of $1000,1100,1200,1300$ and $1400{ }^{\circ} \mathrm{C}$ for two hours. The mechanical properties of Ni based electroless Ni plated ceramic and metallic powders reinforced composite samples were determined. In addition, the metallographic evaluation was carried out by XRD analysis and SEM (Scanning Electron Microscope) on the samples. Consequently, the highest density and hardness is obtained composite made from $(1,66 \% \mathrm{BN}+31,65 \%$ Astaloy-CrM $)+$ $66,67 \% \mathrm{Ni}$ powders, It was sintered at temperature of $1400^{\circ} \mathrm{C}$ for two hour in tube furnace.
\end{abstract}

Keywords: Ceramic Metal Composite, Coating, Powder metallurgy

\section{INTRODUCTION}

Industrial developments require the control of the mechanical, metallographic and electrical properties of materials to obtain new products. Astaloy CrM is a pre-alloy powder released by Höganäs $\mathrm{AB}$ and recently launched[1]. The development of cost effective powder types to obtain high performance structural parts has been an important factor in the growth of the PM industry [2]. Composite materials are used more and more in daily life. Industrial development brings with it the need for new materials every day. When it comes to obtaining more than one feature together, composite materials are at the forefront of the material groups. For example; composite materials are at the top when it comes to producing lighter and more durable materials by improving the mechanical properties of the materials produced in the industry. In composite materials, the main matrix and reinforcement element are defined and known according to the material group and the morphology of the reinforcement elements.

Electroless nickel plating process or nickel coating is used in many areas in industrial applications. It is reported that high performance abrasion resistance was provided by using

*Corresponding Author : yonetken@aku.edu.tr

Received: 05.03.2019 Published: 31.03.2020 
the electroless nickel plating technique in the production of materials [3]. Electroless nickel plating process is the chemical coating of nickel and its alloys on metal surfaces without using electric current by the immersion method. Since the electric current has not been equal on all surfaces, it is not possible to make a regular, homogeneous, and same thickness coating. In addition, non-current nickel plating in ceramic materials ensures sintering at low temperatures. It is signed by Ziegler Sautter, F.J [4]., the electroless nickel coatings are extensively operated to protect the surfaces of metal and its components used in engineering against wear and tear.

One of the ways to increase the resistance of the surfaces of the materials against abrasion and tear is to increase the hardness of the surface by coating. The high performance abrasion resistance can be achieved by using the electroless nickel plating technique in the production of materials. It has been reported that the hardness of the composites produced by the electroless $\mathrm{Ni}$ coating is increased by the addition of ceramic powders while the hardness is decreased with the contribution of metal materials [5-10]. Tungsten, boron, and silicon nitrites have been used in many industrial implementations over the years. In fact that, the ceramic materials are very hard and have great wear resistance and also oxidation of resistance [11]. Small-grain metallic materials with high strength are both theoretically and experimentally interesting. It is possible to improve the mechanical properties due to the strengthening of the ceramic particles [12-17]. Commonly used carbide ceramics due to abrasion resistance have often been used in cutting tools [18-20]. In a different study, thermo chemical processing mechanical properties and impact energy of Astaloy CrM It was investigated. Positive results were obtained [21].

The purpose of the study is to strengthen the Astaloy CrM powder material used as a casting material in the industry with the contribution of $\mathrm{BN}$ ceramic powders and increase its strength. It is intended to be used in friction parts in the cast materials produced. The intensive literature survey revealed that there is a lack of the knowledge about effect of electroless $\mathrm{Ni}$ plating on the properties of $\mathrm{BN}$ ceramic and Astaloy $\mathrm{Cr}-\mathrm{M}$ metallic powders reinforced nickel based composites. The aim of this study is to determine the effect of electroless Ni coating on the properties of $\mathrm{BN}$ ceramic and Astaloy $\mathrm{Cr}-\mathrm{M}$ metallic powders used reinforcement in nickel based composite. Because of this, the electroless Ni coating technique was applied to BN ceramics and commercially Astaloy Cr-M casting powders which are used reinforcement, to obtain nickel based composites. In order to determine the effect of electroless Ni coating on the properties of $\mathrm{BN}$ ceramic and Astaloy $\mathrm{Cr}-\mathrm{M}$ powders that used reinforcement in nickel based composites $(1,66 \% \mathrm{BN}+31,65 \%$ Astaloy-CrM $+\% 66,67 \mathrm{Ni})$ which are obtained sintering at different temperatures for two hours, the mechanical properties has been assessed by hardness measurement and metallographic examination was carried out by X-ray and SEM devices.

\section{EXPERIMENTAL METHOD}

Metallic and ceramic powders used for reinforcement to production of nickel base composite in this study. Nickel coated powders are used as reinforcement in base composite. They were as follows: BN powders of $99.8 \%$ purity with a particle size of less than $50 \mu \mathrm{m}$ were used as ceramic powder. The commercial Astaloy-CrM powders having a size of less than $50 \mu \mathrm{m}$ were used as metallic powder. The chemical compositions of both powders are given in Table 1. 
Yönetken / Eskişehir Technical Univ. J. of Sci. and Tech. A-Appl. Sci. and Eng. 21 (1)-2020

Table 1. The chemical composition of Astaloy Cr-M metallic and BN ceramic powders (\%wt).

\begin{tabular}{clllllllll}
\hline Powder & $\mathrm{Al}_{2} \mathrm{O}_{3}$ & $\mathrm{~F}_{3} \mathrm{O}$ & $\mathrm{SiO}_{2}$ & $\mathrm{CaO}$ & $\mathrm{MgO}$ & $\mathrm{Na}_{2} \mathrm{O}$ & $\mathrm{K}_{2} \mathrm{O}$ & $\mathrm{TiO}_{2}$ & LOI \\
\hline Astaloy Cr- & $55-$ & $19.95-$ & $3.15-$ & $0.27-$ & $0.02-$ & $0,06-$ & $0.12-$ & $2.66-$ & $9.7-$ \\
$\mathrm{M}$ & 60.35 & 22.85 & 6.95 & 3.90 & 0.04 & 0.16 & 0.27 & 3.27 & 11.58 \\
& $99.8 \%$ & & & & & & & & \\
$\mathrm{BN}$ & $\begin{array}{l}\text { purity) } \\
\end{array}$ & & & & & & & & \\
\hline
\end{tabular}

The nickel base composite was produced with an electroless Ni coated ceramic and metallic powders $(1,66 \mathrm{BN}$ ceramic $+31.65 \%$ Astaloy-CrM metallic powders $+\% 66,67 \mathrm{Ni})$. The $\mathrm{Ni}$ coating was obtained by suspending the initial Astaloy $\mathrm{Cr}-\mathrm{M}$, metallic, and $\mathrm{BN}$, ceramic, powders in a $\mathrm{Ni}$ containing solution $\left(\mathrm{N}_{2} \mathrm{H}_{4} \cdot \mathrm{H}_{2} \mathrm{O}\right)$ at the temperature of $90-95^{\circ} \mathrm{C}$, by adding hydrazine hydrate $\left(\mathrm{N}_{2} \mathrm{H}_{4} \cdot \mathrm{H}_{2} \mathrm{O}\right)$ and $35 \%$ volume percent ammonia solutions. Meanwhile, the $\mathrm{pH}$ of the bath has been maintained in the range of 9-10 with rising temperature. Since the ammonia-evaporation rate has been extended quickly, a dripper was used to add more ammonia to adjust the $\mathrm{pH}$ of the coating solution. The content and conditions of the electroless Ni coating bath ratio are given in Table 2.

Table 2. The chemicals of Nickel plating bath and ratios

\begin{tabular}{cc}
\hline Chemicals & Conditions \\
\hline Astaloy Cr-M & $12 \mathrm{~g}$ \\
Boron Nitride $(\mathrm{BN})$ & $3 \mathrm{~g}$ \\
*Nickel Chloride $\left(\mathrm{NiCI}_{2} \cdot 6 \mathrm{H}_{2} \mathrm{O}\right)$ & $60 \mathrm{~g}$ \\
Hydranize Hydrate $\left(\mathrm{N}_{2} \mathrm{H}_{4}, \mathrm{H}_{2} \mathrm{O}\right)$ & $20 \%$ \\
Distilled Water & $80 \%$ \\
Temp. & $90-95^{\circ} \mathrm{C}$ \\
pH Value & $9-10$ \\
\hline
\end{tabular}

Meanwhile, the solution was stirred continuously, and the $\mathrm{pH}$ was continuously monitored using a Philips PW 9413 Ion Activity Meter. The reaction was permitted to continue until enough $\mathrm{Ni}$ was deposited to coating all Astaloy $\mathrm{Cr}-\mathrm{M}$ metallic and $\mathrm{BN}$ ceramic powders. After that, the Ni-coated Astaloy $\mathrm{Cr}-\mathrm{M}$ metallic and $\mathrm{BN}$ ceramic powders were filtered through the solution using a paper filter and washed repeatedly. The Ni coated powders were cleaned with distilled water and dried in an oven at the temperature of $105^{\circ} \mathrm{C}$ for 24 hours. The resulting powders has been get ready for shaping in a cylindrical mold and sintering at $1000-1400^{\circ} \mathrm{C}$ for 2 hour using a conventional tube furnace.

In order to produce composite, the electroless $\mathrm{Ni}$ coated powders and nickel were formed under a pressure of 300 Bar in a uniaxial cold press. Later, the shaped raw samples were sintered in the traditional heat treatment furnace under argon atmosphere and sintering gas flow rate $2 \mathrm{lt} / \mathrm{h}$ at the temperatures of $1000^{\circ} \mathrm{C}, 1100^{\circ} \mathrm{C}, 1200^{\circ} \mathrm{C}, 1300^{\circ} \mathrm{C}$, and $1400^{\circ} \mathrm{C}$ for two hours. The powder materials were hold at the temperature determined as sintering time for 2 hours. The duration of bleaching can be determined longer, but has been determined with energy loss and cost in mind. The sintered samples were arranged for hardness measurement for determining mechanical properties and the samples were prepared by using grinding and polishing processes for metallographic analysis. The samples which were prepared to a $1 \mu \mathrm{m}$ finish using diamond paste and not etched prior to metallurgical examination in SEM. 
The phases and precipitates formed in the sintered composite samples were determined by XRD analysis. Shimadzu XRD-6000 X-Ray Diffraction analyzer was run with $\mathrm{Cu} \mathrm{K}$ alpha radiation at the scanning rate of 2 degree per min.

Scanning Electron Microscope which is LEO 1430 VP model is used and also Oxford EDX analyser was operated for microstructural analyses for evaluation of metallographic characteristics.

The density of obtained composite was measured by Archimedes principle using these data. The hardness of the nickel base composite which are produced by electroless Ni coated $\mathrm{Bn}$ ceramic and Astaloy Cr-M metallic powders reinforcement at the different sintering temperatures were measured by Shimadzu hardness testing machine. The $200 \mathrm{~g}$ load is applied on the intender. In order to minimize error, a set of 10 measurements was taken for each obtained composites hardness machine with a load of $200 \mathrm{~g}$ and time duration of 10 second.

\section{RESULTS AND DISCUSSION}

\subsection{Characterization of Samples}

In order to produce composite, the electroless $\mathrm{Ni}$ coated powders and nickel were shaped under a pressure of $300 \mathrm{Bar}$ in a uniaxial cold press and then samples were sintered in the traditional furnace at the temperatures of $1000^{\circ} \mathrm{C}, 1100^{\circ} \mathrm{C}, 1200^{\circ} \mathrm{C}, 1300^{\circ} \mathrm{C}$ and $1400^{\circ} \mathrm{C}$. In terms of determining an effect of sintering temperature on the density of composite, the density of samples was measured by Archimedes principle method. The temperature dependent density replacements graphic is given in Figure 1.

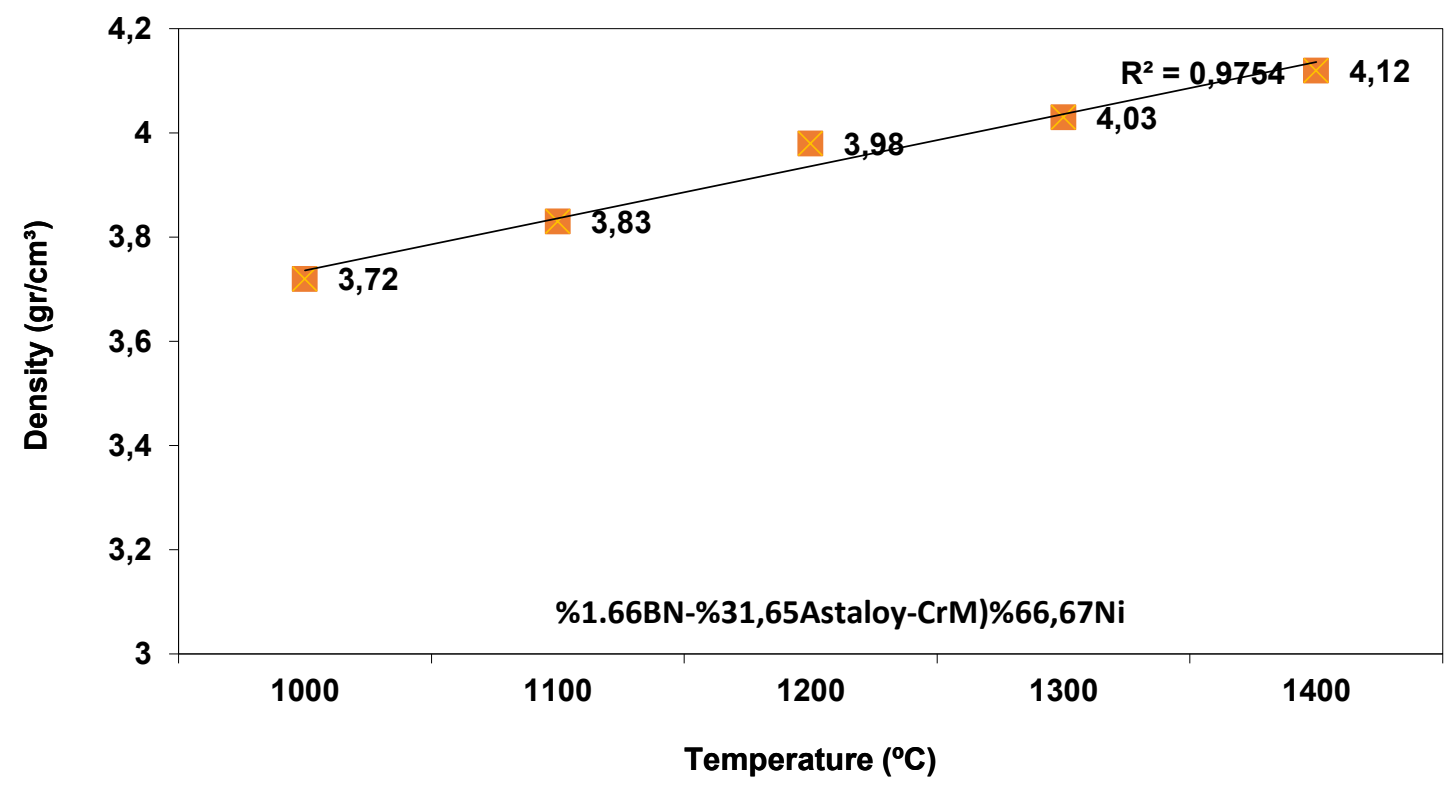

Figure 1. The relationship between density and sintering temperatures for $(\% 1.66 \mathrm{BN}+\% 31,65 \mathrm{Astaloy}-\mathrm{CrM}$ powders reinforced) $+\% 66,67 \mathrm{Ni}$ based composites

As is seen Figure 1, the density of composite increases with rising sintering temperature. The curve shows a near-linear change. The highest sintered density is calculated as $4,12 \mathrm{gr} / \mathrm{cm}^{3}$ for composite that was sintered at the temperature of $1400{ }^{\circ} \mathrm{C}$ for 2 hours. It is believed that the temperature plays important role in regard to diffusion of air in the cold pressed sample and joining of the powders to contact each others during the sintering. Pure Ni deposition occurs on Astaloy CrM powders and BN 
powders after coating in the produced composition. Electroless $\mathrm{Ni}$ coating reduces the sintering temperature of ceramic powders. It enables energy saving and low temperature composite production. Ni particles, which precipitate during sintering, ensure the bonding of ceramic particles by forming a neck. It causes an increase in density by closing the pores between the ceramic particles.

Moreover, Ni phase plays an important role in increasing the composite density. The composite contains $50 \%$ of the composition by weight. The effect of sintering temperature on the mechanical properties such as; hardness of composite, the hardness of samples was measured. Results are indicated graphically in Figure 2.

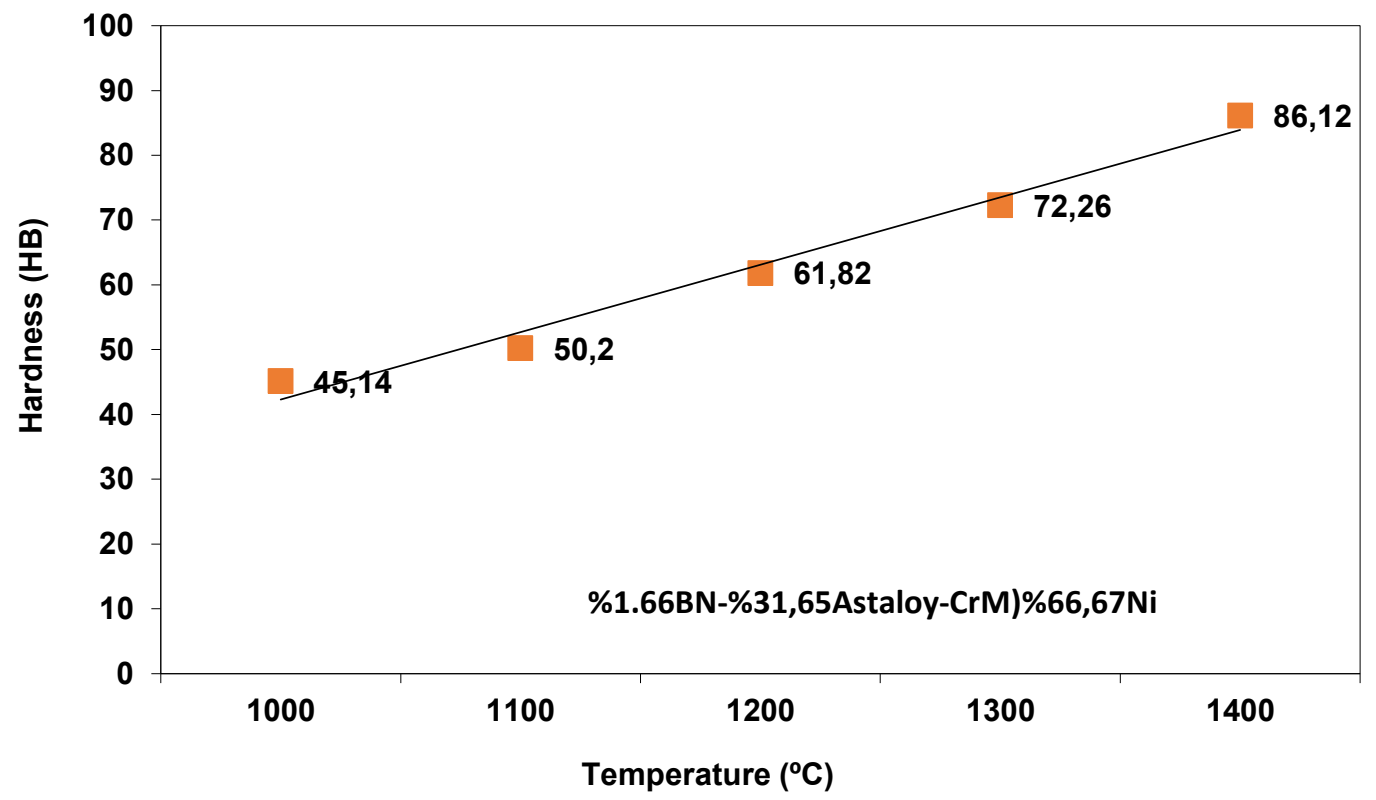

Figure 2. The hardness of composites sintered at different temperatures for two hours

As is seen in Figure 2, in composite (AstaloyCr-M + BN powders reinforced + Nickel based) sample, the lowest hardness was measured at $45.14 \mathrm{HB}$ in the sample sintered at $1000^{\circ} \mathrm{C}$ temperature, while the highest hardness was measured as $86.12 \mathrm{HB}$ in the sample sintered at $1400{ }^{\circ} \mathrm{C}$ for two hours. The results also indicates that hardness of the composites increasing with sintering temperature. It can be explained by pasess and precipitates formed at that temperature.

Moreover, the rising in hardness so; the strength values give hope for the relatively high stiffness composite materials with a limited ductile property.

\subsection{Microstructure Evaulation}

The microstructure of nickel-plated BN ceramic and Astoloy CrM metallic powder reinforced nickelbased composite material which were sintered at the various temperatures for two hours was investigated using the scanning electron microscope for metallographic characterization. The microstructure of the composites which were sintered at the temperature of $1000{ }^{\circ} \mathrm{C}$ and $1400{ }^{\circ} \mathrm{C}$, were shown in Figure 3 and Figure 4 respectively. 


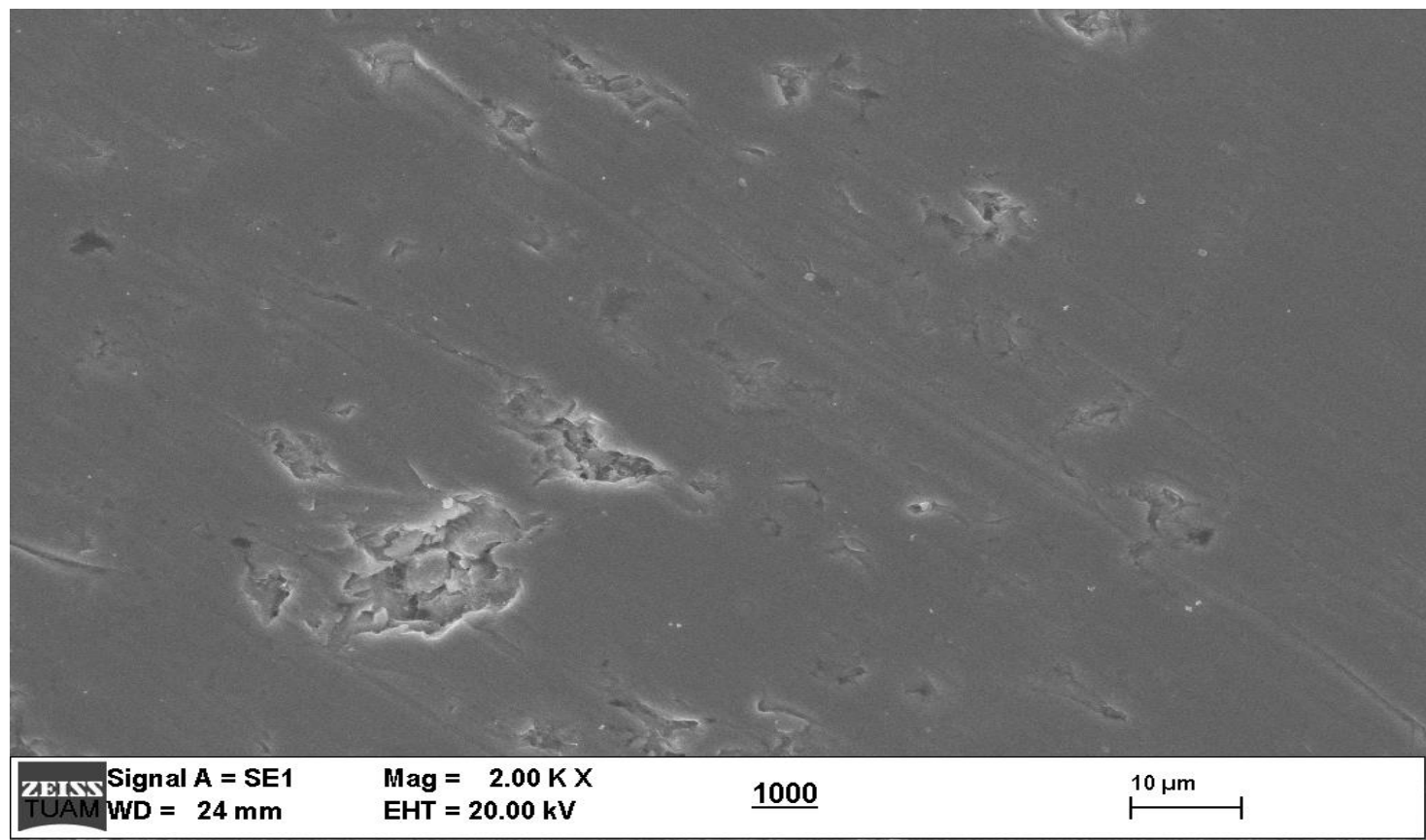

Figure 3.SEM micrographs of composite sintered at the temperature of $1000^{\circ} \mathrm{C}$ for two hours.

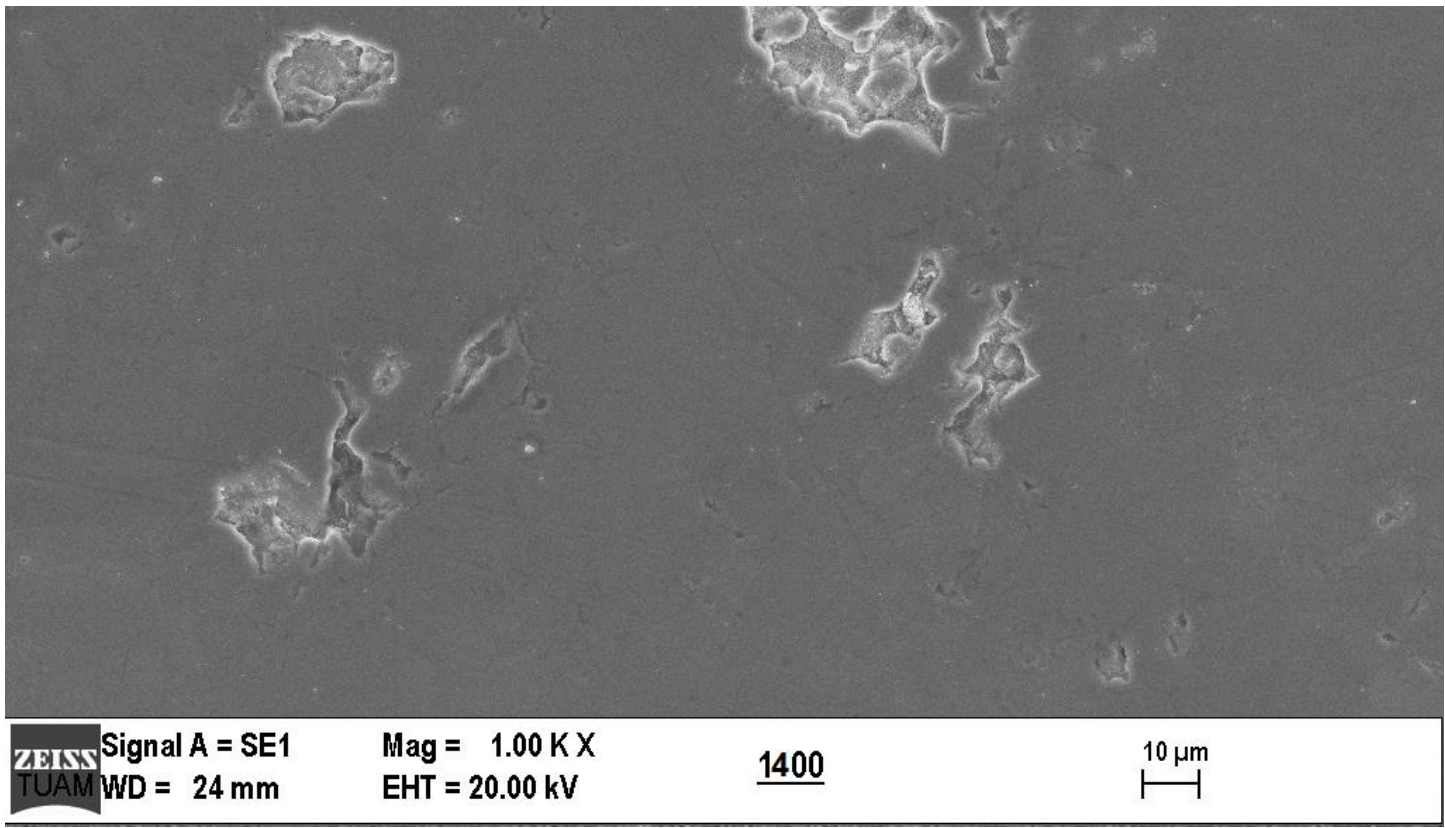

Figure 4. SEM micrographs of composite sintered at the temperature of $1400^{\circ} \mathrm{C}$ for two hours.

As is seen Figures 3 and 4, the nickel base composite microstructure was decorated with electroless nickel plated Astaloy-CrM metalic and BN ceramic powders particles reinforcement. It was also observed that the reinforcement powders particles in the structure were connected to each other by a neck bond. The particles sizes are coarser. The homogenous distributed pores which envelop the reinforcement particles are observed. An important feature in the microstructure images is the increase in sintering temperature and a decrease in the amount of porosity. It can be revealed by diffusion of air and microjoining of powders with regarding the sintering temperature and time. It is believed that less amount porosity is responsible for high density and the formed phases and precipitates are responsible 
Yönetken / Eskişehir Technical Univ. J. of Sci. and Tech. A-Appl. Sci. and Eng. 21 (1)-2020

for high hardness so desired strength of composite which sintered at the temperature of $1400{ }^{\circ} \mathrm{C}$ for two hours.

The characterization of phases and precipitates formed in the structure is very important for properties of nickel based composite. Therefore, XRD analysis was carried out samples which were sintered at the temperature of $1000{ }^{\circ} \mathrm{C}$ and $1400{ }^{\circ} \mathrm{C}$, for two hours respectively. XRD analysis results are shown in Figure 5 and Figure 6.

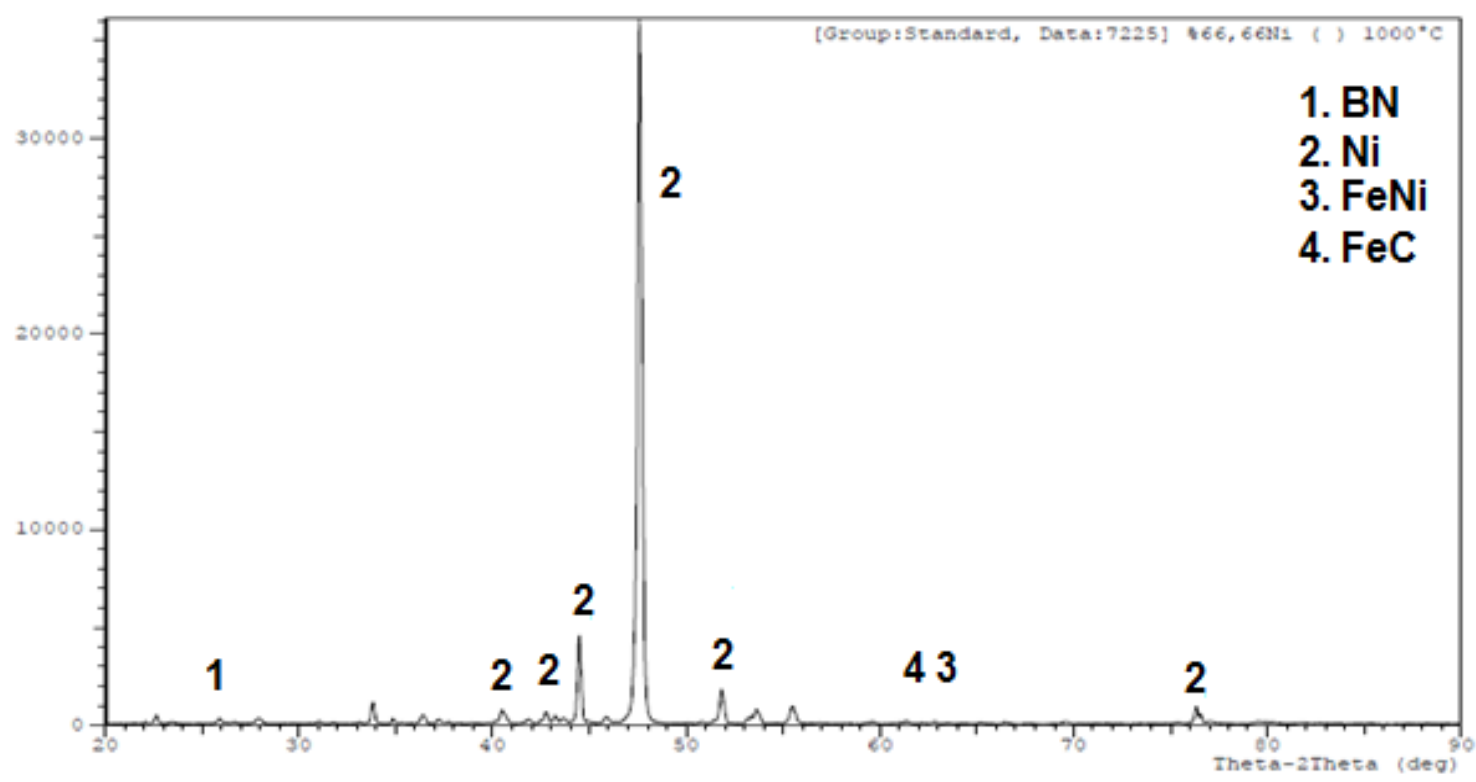

Figure 5. The XRD analysis result of the sample sintered at the temperature of $1000{ }^{\circ} \mathrm{C}$ for two hours.

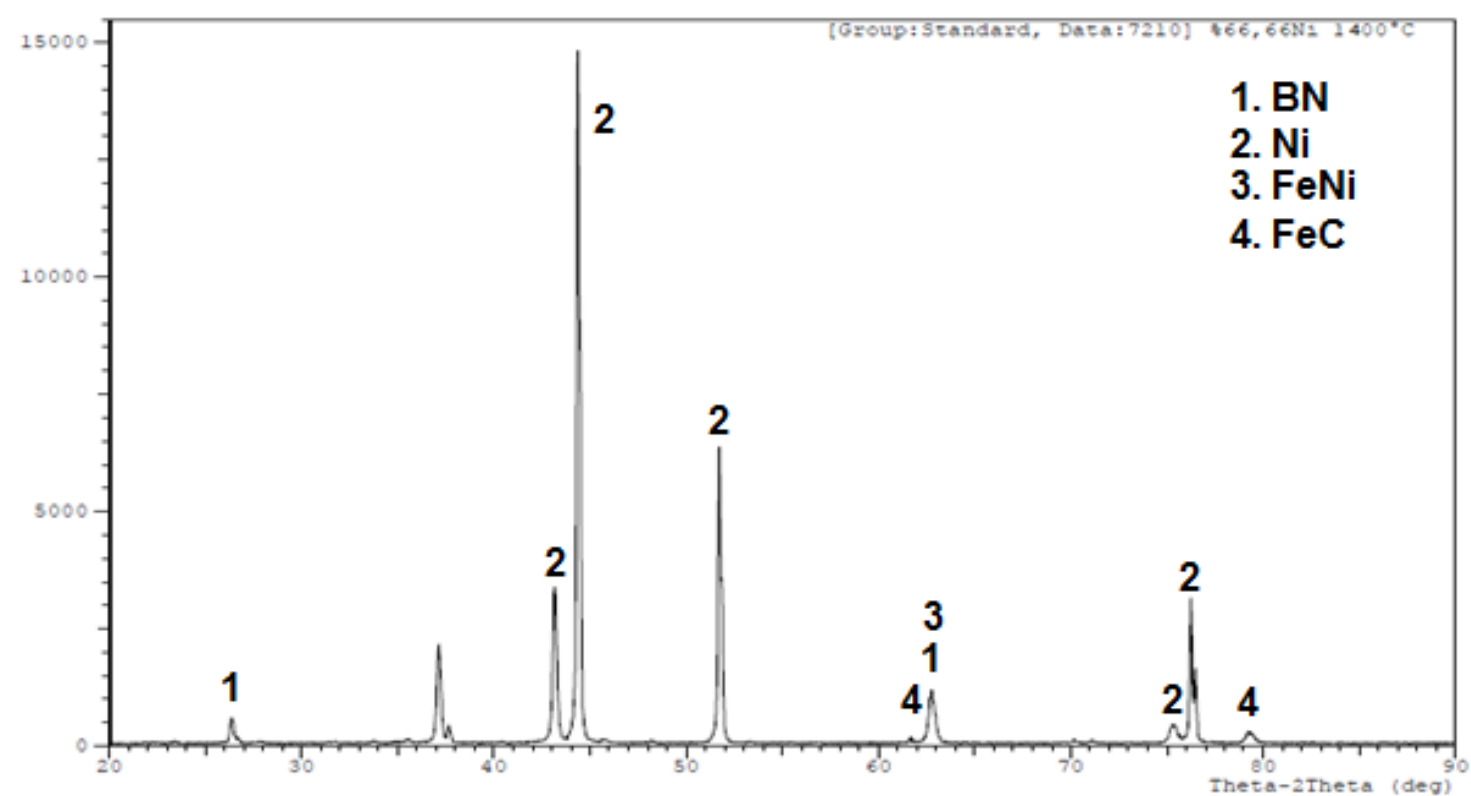

Figure 6. The XRD analysis result of the sample sintered at the temperature of $1400{ }^{\circ} \mathrm{C}$ for two hours.

As is seen Figure 5 and 6, the XRD analysis results makes clear the phases and precipitates formed in the samples. Peaks in the Fig.5 indicate Ni, BN, FeNi and FeC, phases formed sampled sintered at the 
temperature of $1000^{\circ} \mathrm{C}$. Peaks in Figure 6 also indicate Ni, BN, FeNi, and $\mathrm{FeC}$ phases were presented in the sample sintered at the temperature of $1400^{\circ} \mathrm{C}$. The strong nickel peak in the XRD analysis results indicates that the structure consists of nickel matrix, and $\mathrm{BN}$ and $\mathrm{FeNi}, \mathrm{FeC}$ formations occur.

It is important to evaluate the results of XRD analysis carried out on the samples. In terms of support the results with literature studies to determine the phases and formations that occur in the structure. Therefore phases and precipitates were evaluated with regard to the sintering temperatures

\section{CONCLUSION}

The electroless nickel plating technology is less porous than electrolytic coating and provides better corrosion resistance. There is no need for electrical energy for the electroless nickel plating process. This ensures an efficient and cost-effective coating process. A more powerful and high-quality coating does not require final finishing. It provides a great flexibility of coating thickness and coating volume in the coating made by the electroless nickel plating technique. The recesses and pits of the particles to be coated easily fill up properly. It provides great flexibility of coating thickness and coating volume in electroless nickel plating technique. Therefore the effect of electroless $\mathrm{Ni}$ coating on the properties of $\mathrm{BN}$ ceramic and Astaloy Cr-M metallic powders used reinforcement in nickel based composite was investgated in detail.

The findings obtained in the study can be summarized as follows.

- The highest density is obtained composite made from $(1,66 \% \mathrm{BN}+31,65 \%$ Astaloy$\mathrm{CrM})+66,67 \% \mathrm{Ni}$ powders, It was sintered at temperature of $1400^{\circ} \mathrm{C}$ for two hour in tube furnace. The highest density in the sample was figured out as $4,12 \mathrm{gr} / \mathrm{cm}^{3}$.

- The highest hardness in $(1,66 \% \mathrm{BN}+31,65 \%$ AstaloyCrM $)+66,67 \% \mathrm{Ni}$ composite that was manufactured using the powder metallurgy method, was figured out as $86.2 \mathrm{HB}$ in the sample sintered also at temperature of $1400^{\circ} \mathrm{C}$. The highest hardness presents good strength and stiffness as well as desired microstructure.

- The strong nickel peak in the XRD analysis results indicates that the structure consists of nickel matrix, and $\mathrm{BN}$ and $\mathrm{FeNi}, \mathrm{FeC}$ peaks reflect to the formation of precipitates in the nickel base nickel coated BN and Astaloy Cr-M powder particle reinforced composite.

\section{ACKNOWLEDGMENTS}

In this study was supported by the 17 .KARIYER.162 project of Afyon Kocatepe University. I would like to thanks the A.K.U. Scientific Research Coordination Unit.

\section{REFERENCES}

[1] Engstrom U. Milligan, D. Klekovkin, A., “Adv. Powder Metall. Part. Mater.” Part 7(2006) 21.

[2] Teimouri M, Ahmadi M., Pirayesh N., Aliofkhazraei M., Mousavi Khoee M., Khorsand H., Mirzamohammadi S., Study of corrosion behavior for nitrocarburized sintered Astaloy $\mathrm{CrM}{ }^{\circledR}+\mathrm{C}$, Journal of Alloys and Compounds 477 (2009) 591-595.

[3] Grazen, A.E., Iron Age. 183;1959;944.

[4] Ziegler Sautter, F.J., Electrochem. Soc. $110 ; 1963 ; 575$

[5] Fink, C.G., Trans. Am. Electrochem. Soc. 54;1928; 315. 
[6] Edwards, J.A., Prod. Finish. 2 ; 1959; 66.

[7] Williams, R.V., Electroplat. Metal Finish. 19 ;1966; 927.

[8] Greco, V.P., Baldauf, W. Plating, $55 ; 1968 ; 2508$.

[9] Weimer A. W., Carbide, Nitride and Boride Materials Synthesis and Processing, Springer, 1997; P671 ISBN 0412540606.

[10] Yönetken A, Erol A, Production And Characterization Of Al-BN Composite Materials Using By Powder Metallurgy. Agronomy Research, 16; 2018; 1289-1293., Doi: http://dx.doi.org/10.15159/ar.18.135.

[11] Zhang Q., Wu1, M., and Z. Wen 'Electroless nickel plating on hollow glass microspheres, Surface \& Coatings Technology’ 192;2005;213-219.

[12] Trojanová Z., Lukác c P., Ferkel H.and Riehemann W., Internal Friction in Microcrystalline and Nanocrystalline Mg. Materials Science and Engineering A 370; 2004; P154-157.

[13] Gaard A., Krakhmalev P., Bergstrom J., Microstructural characterization and wear behavior of (Fe,Ni)-TiC MMC prepared by DMLS, Journal of Alloys and Compounds, 421; 2006; p166171.

[14] V. Richter and M.V. Ruthendorf, J. Ref. Met. And Mater. 17; 1999; 141-152.

[15] Yönetken, A., Erol A., "The Effect of Microwave Sintering on the Properties of Electroless Ni Plated WC-Fe-Ni Composites", Science And Engineering of Composite Materials, 17/3; 2010; 191-199.

[16] A. Erol, A. Yönetken, "Fabrication of Electroless Ni plated Fe-TiC Metal Matrix Composites", Science And Engineering of Composite Materials, 18/3; 2011; 145-149.

[17] Li T., Li Q., Fuha J.Y.H., Poh Ching Y., Wu C.C., Effects Of Lower Cobalt Binder Concentrations In Sintering Of Tungsten Carbide, Materials Science And Engineering A, Volume: 430; 2006; 113-119.

[18] Yuhong X., Ki L., Xiaoying Z., Schoenung Julie M., “A Streamlined Life Cycle Assessment On The Fabrication Of WC-Co Cermets, Journal Of Cleaner Production", Volume:16; 2008; 11181126.

[19] Taheri-Nassaj, E., Mirhosseini, S.H., "An In Situ WC-Ni Composite Fabricated By The SHS Method”, Journal Of Materials Processing Technology, Volume: 142; 2003; 422-426.

[20] Upadhyaya G.S., Bhaumik S.K., Sintering Of Submicron WC-10\% Co Hard Metals Containing Ni And Fe, Materyal Sciences Engineering-A, V:249; 1988; 105-106.

[21] Mansoorzadeh S., Ashrafizadeh F., " The effect of thermochemical treatments on case propertiesand impact behaviour of Astaloy CrM" Surface \& Coatings Technology 192 (2005) $231-238$ 